\title{
Combination therapy of Allium cepa L. and Cucumis sativa L. extracts in streptozotocin-induced diabetic rat model
}

\author{
O. M. Ighodaro ${ }^{1 *}$, A. M. Adeosun ${ }^{1}$, T. S. Ujomu², O. O. Durosinlorun ${ }^{1}$ and C. C. Okosa ${ }^{1}$
}

\begin{abstract}
Background: The study assessed the effects of aqueous extracts of Allium cepa, Cucumis sativa and their combined formulation (1:1) on changes in body weight, fasting blood glucose level (FBGL), pancreas morphology and serum lipid concentration in streptozotocin-induced diabetic rats. Forty-two male rats were randomly assigned to six groups: A, B, C, D, E, and F ( $n=7)$. Except for the control animals (group A), diabetes mellitus was experimentally induced in other groups ( $B$ to F) via a single intraperitoneal injection of freshly prepared streptozotocin. Thereafter, the diabetic control animals (group B) were left untreated and other diabetic groups were treated as follows: C (Allium cepa $10 \mathrm{~mL}$ / $\mathrm{kg}$ of body weight (mL/kg BW), D (Cucumis sativa $10 \mathrm{~mL} / \mathrm{kg} \mathrm{BW}$ ), E (Allium cepa and Cucumis sativa $10 \mathrm{~mL} / \mathrm{kg} \mathrm{BW}$ ), and $\mathrm{F}$ (Metformin $12 \mathrm{mg} / \mathrm{kg} \mathrm{BW}$ ). All treatments lasted for seven days and FBGL was monitored at two days intervals. The rats were then sacrificed, and blood samples were collected for serum lipid estimation.

Results: Treatments of diabetic rats with Allium cepa, Cucumis sativa and their combined formulation prevented significant $(P<0.05)$ loss in body weight which was evident in the diabetic control counterparts. Similarly, the various treatment options curtailed the hike in blood glucose induced by streptozotocin. The hypoglycemic effect of Allium cepa was particularly notable and comparable to that of Metformin. Serum high-density lipoprotein and low-density lipoprotein-cholesterols which were significantly altered in the diabetic control animals were restored to near normal following treatments with Cucumis sativa, and its combination with Allium cepa. These observations were substantiated by the outcome of the histopathological examination of the representative pancreases.

Conclusion: Allium cepa appears to be more effective in blood glucose homeostasis in the diabetic animals compared to Cucumis sativa and their combined formulation. Conversely, Cucumis sativa and its combination with Allium cepa had better effects on the physiological levels of serum cholesterols in the animals. Regular consumption of Allium cepa and Cucumis sativa may be helpful in controlling blood glucose and cholesterol levels in the diabetics.
\end{abstract}

Keywords: Allium cepa, Cucumis sativa, Streptozotocin, Diabetes, Wistar rats

\section{Background}

Diabetes mellitus is not a single disorder. It represents a series of metabolic conditions associated with hyperglycemia due to defects in insulin secretion or insulin action [1]. The disease is of two major types, Type1 and type 2. The type 2 diabetes mellitus is a major public health

\footnotetext{
*Correspondence: macigho@gmail.com

${ }^{1}$ Department of Biochemistry, Lead City University, Ibadan, Nigeria

Full list of author information is available at the end of the article
}

problem worldwide, as it constitutes over $95 \%$ of diabetes cases. Current global estimate indicates that this condition affects about 415 million people and is projected to escalate to 642 million by the year 2040 [2]. Age is one of the most important risk factors for type 2 diabetes; however the disease has become prevalent among all age groups. In sub-Saharan Africa, Nigeria has the highest number of people with diabetes. An estimate of 3.9 million people (extrapolated prevalence of $4.99 \%$ ) among population aged 20-79 years old has been reported to be 
suffering from diabetes [3]. There are a number of therapeutic options available for the management of diabetes mellitus yet the disease currently has no cure. It is now popular knowledge that diet plays a significant role in health and diseases [4]. The kind of diet we consume may put us in either health or disease status. In recent times, there has been an exponential increase in the number of established fast food centers in Nigeria, consequently contributing to the availability of unhealthy diets with high calorie content and unhealthy fats [5]. Additionally, studies in Africa indicate low adherence to dietary recommendation for macronutrients, fruits and vegetables consumption among diabetic patients [6]. Consumption of vegetables and fruits has been known to contribute to health, and protect against diseases. Vegetables play a remarkable role in human nutrition and health since they contain dietary fiber, phytochemicals, vitamins and minerals [7]. Nutritious vegetables like cucumber (Cucumis sativa) which is also regarded as fruit contains high fiber, vitamins, and low calorie content which may play key roles in lowering blood sugar level. It also helps to slow down digestion of carbohydrates, which may further lower blood sugar levels. Cucumbers are also good sources of plants chemicals with disease-preventive properties called phytonutrients (flavonoids, ligands and triterpenes) [8] Also, onions (Allium cepa) as a vegetable contain low calorie content, high fiber, vitamins, various antioxidants and specific compounds such as quercetin which may help to lower blood glucose level. Moreover, it helps in reducing the pace at which carbohydrates are released into the blood, a process which regulates the sugar level in the body [9]

More importantly, there are folklore claims that onions and cucumber help in regulating the level of blood sugar, and these claims have been substantiated by some previous reports [10-12]

It is on this basis that the present study sought to evaluate the relative efficacy of the combination therapy of Allium cepa and Cucumis sativa extracts in the treatment of diabetes mellitus.

\section{Methods}

\section{Collection and management of animals}

Forty-two (42) adult male Wistar rats with body weights ranging from 140 to $160 \mathrm{~g}$ were purchased from Covenant Farm, Olodo, Ibadan. The animals were acclimatized in the Departmental animal house under suitable environmental conditions and were housed in plastic cages with wire net. The animals were acclimatized for 14 days and were fed with Top feeds (Animal feed) and water adlibitum throughout the study.

\section{Sample collection and preparation of extracts}

Cucumber and Onion were obtained from Orita Market, Challenge Road, Ibadan, Nigeria. The samples were identified and authenticated by a curator botanist. Five hundred (500) grams each of cucumber and onions were separately washed, weighed and blended with $50 \mathrm{~mL}$ of water. The blended samples were stirred intermittently and filtered to obtain freshly prepared aqueous juice extracts.

\section{Animal treatment and grouping}

The animals were randomly assigned to seven groups $(n=7)$. Group A and F were normoglycemic; others (B-F) were made diabetic by intra-peritoneal injection of freshly prepared streptozotocin in citrate buffer $\mathrm{pH}$ 4.5 at a dose of $55 \mathrm{mg} / \mathrm{kg}$ BW. Diabetes was confirmed in the rats $48 \mathrm{~h}$ after streptozotocin injection using AccuChek Active glucometer with disposable test strips. Animals with fasting blood glucose levels of $200 \mathrm{mg} / \mathrm{dL}$ and above were considered diabetic and included in the study. Treatments were assigned as presented in Table 1 .

Fasting blood glucose was monitored at two days intervals over a period of seven days via the tails of the rats. Blood sample was collected by ocular puncture from each rat into plain tubes. Serum was separated from the whole blood by centrifuging at $4000 \mathrm{rpm}$ for $10 \mathrm{~min}$ and stored at $4{ }^{\circ} \mathrm{C}$ for biochemical analyses. The rats were sacrificed by cervical dislocation; pancreas was excised for histopathological examination.

Table 1 Experimental design and treatments of animals in groups

\begin{tabular}{|c|c|c|}
\hline Groups & Treatments & Nomenclature \\
\hline Group A & Normoglycemic, untreated & CN \\
\hline Group B & Diabetic, untreated & DC \\
\hline Group C & Diabetic, treated with Allium cepa alone & $A C$ \\
\hline Group D & Diabetic, treated with Cucumis sativa alone & CS \\
\hline Group E & Diabetic, treated with both Allium cepa and Cucumis sativa & $A C+C S$ \\
\hline Group F & Diabetic, treated with metformin 12 mg/kg BW & MET \\
\hline
\end{tabular}

CN, Normal control; DC, Diabetic control; AC, Allium cepa; CS, Cucumis sativa, Met, Metformin 


\section{Estimation of lipid concentration}

The sera obtained above were used for the biochemical analyses of total cholesterol, triglycerides, low-density lipoprotein (LDL) cholesterol, and high-density lipoprotein (HDL) cholesterol using clinical diagnostic kits (Biobase, Jinan, China). Total cholesterol was determined using method by Allain et al. [13]. Triglycerides were determined using the methods of Fossati and Principe [14]. Determination of LDL-Cholesterol was done using immunoturbidimetric method described by McNamara et al. [15] and the method of Lopez-Virella [16] was used to estimate HDL-cholesterol. The LDL-HDL ratio for each group was estimated mathematically.

\section{Histopathological processing and examination}

Histopathological processing and examination of the pancreas was carried out as described by Avwioro [17].

\section{Statistical analysis}

Data analysis was performed using statistical software, Prism graphpad, version 6.4. The statistical significance of difference between groups was analyzed using the oneway analysis of variance (ANOVA), followed by independent-sample $t$ test. The level of significance was set at $P<0.05$. The results were presented as the mean \pm SD.

\section{Results}

Streptozotocin markedly caused reduction in the body weights of the rats. Treatments of diabetic rats with allium cepa and cucumis sativa aqueous extracts and their combination at a dosage of $10 \mathrm{~mL} / \mathrm{kg}$ of body weight $(\mathrm{BW})$ via oral route (p.o), twice daily at $8 \mathrm{~h}$ interval for 7 days moderated the body weights of the rats (Fig. 1).
As shown in Fig. 2: Group A (CN) had a stable fasting blood glucose level which ranged from $80 \mathrm{mg} / \mathrm{dL}$ to $100 \mathrm{mg} / \mathrm{dL}$. The group showed normoglycemic levels of blood glucose all through the duration of the study. On day 1, rats in group B-F had markedly increased blood glucose concentration ( $\geq 200 \mathrm{mg} / \mathrm{dL}$ ) as a result of streptozotocin injection. Allium cepa reduced fasting blood glucose concentration in a manner similar to Metformin, the combination of Allium cepa and Cucumis sativa were only able to reduce fasting blood glucose to a value $(120 \mathrm{mg} / \mathrm{dL})$ still slightly above the upper limit $(100 \mathrm{mg} /$ $\mathrm{dL}$ ) of normal glucose level after 7 days of treatment. Figure 3 indicates that serum total cholesterol levels were

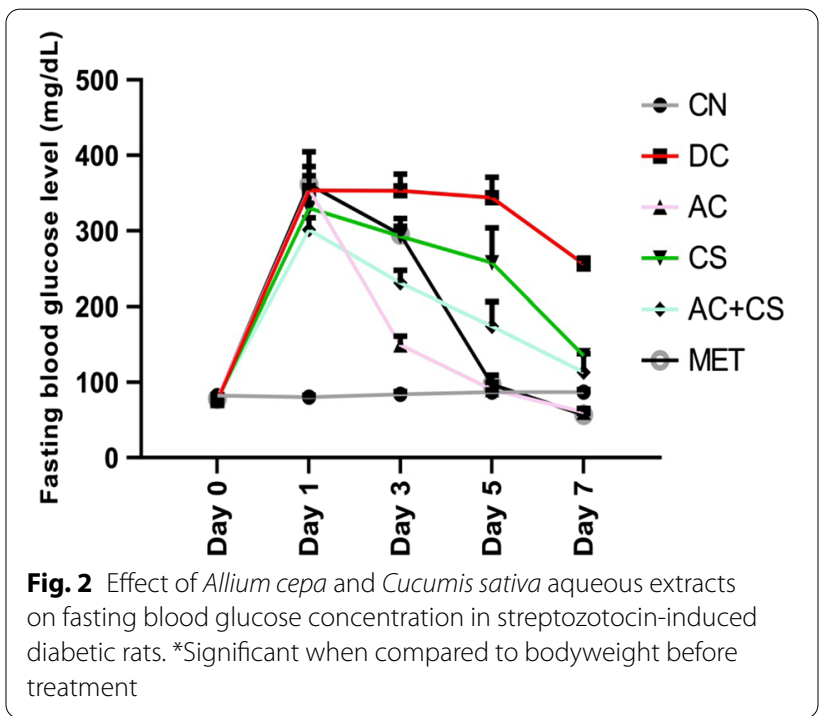

Fig. 3 Effect of Allium cepa and Cucumis sativa aqueous extracts on serum total cholesterol concentration in streptozotocin-induced diabetic rats. a significant when compared with control (CN), b significant when compared with diabetic control (DC) 
increased in rats treated with aqueous extracts of allium cepa and cucumis sativa and their combination.

As shown in Fig. 4 serum HDL-cholesterol level was significantly $(P<0.05)$ reduced in untreated diabetic rats; however, aqueous extract of cucumis sativa and its combination with allium cepa significantly increase HDL-cholesterol concentration in a manner comparable to Metformin. Serum triglyceride levels were noticed to increase in rats treated with Cucumis sativa and its combination with Allium cepa (Fig. 5).

As shown in Fig. 6 serum LDL-cholesterol levels were significantly $(P<0.05)$ reduced in rats treated with aqueous extracts of Cucumis sativa and its combination with Allium cepa in comparable manner with Metformin.

\section{Photomicrographs of the thin sections of pancreas of the different groups of animals}

The results of the histopathological examination of representative pancreas sections of the different groups of animals (control and treated) are shown in Fig. 7A-E.

Pancreas sections of group A animals (control group) show normal serous acinar and zymogenic cells (slender arrow) containing abundant granular eosinophilic cytoplasm and normal interlobular connective tissues (blue arrow). There are normal compact islets of Langerhans (white arrow) consisting of round to oval collections of endocrine cells.

Group B animals (Diabetic control group) showed poor architecture of the parenchyma with acinar ectasia, degenerated acinar and zymogenic cells with vacuolation and dilatation are seen (slender arrow). There

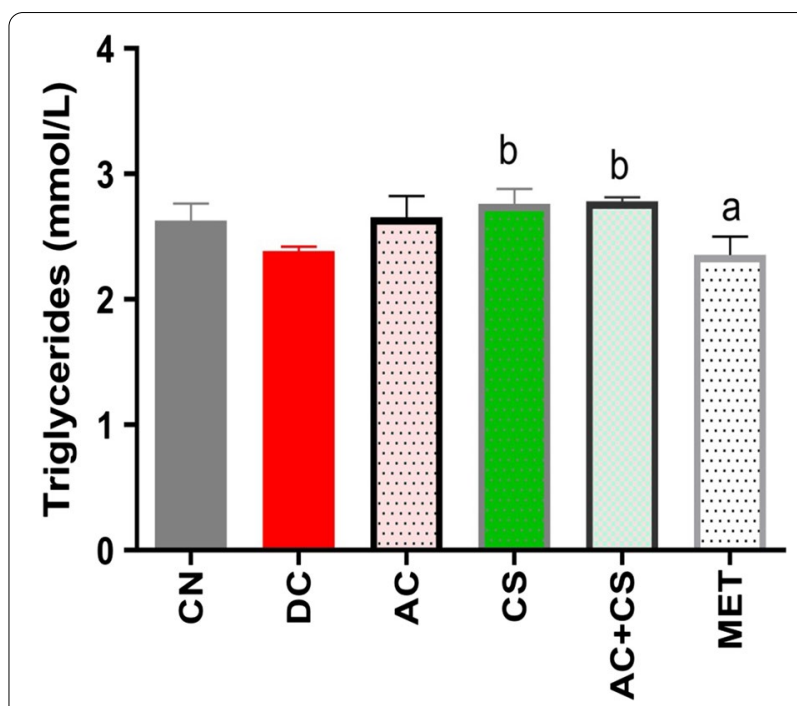

Fig. 5 Effect of Allium cepa and Cucumis sativa aqueous extracts on serum triglyceride concentration in streptozotocin-induced diabetic rats. a significant when compared with control (CN), b significant when compared with diabetic control (DC)

are islets of Langerhans with ill-defined margin (white arrow) consisting of degenerated endocrine cells.

Group $\mathrm{C}$ animals (Diabetic animals treated with Allium cepa $(10 \mathrm{~mL} / \mathrm{kg}$ BW) showed normal acinar cells (slender arrow) containing abundant granular eosinophilic cytoplasm, normal interlobular connective tissues (blue arrow). There are normal compact islets of Langerhans (white arrow) consisting of round to oval collections of endocrine cells.

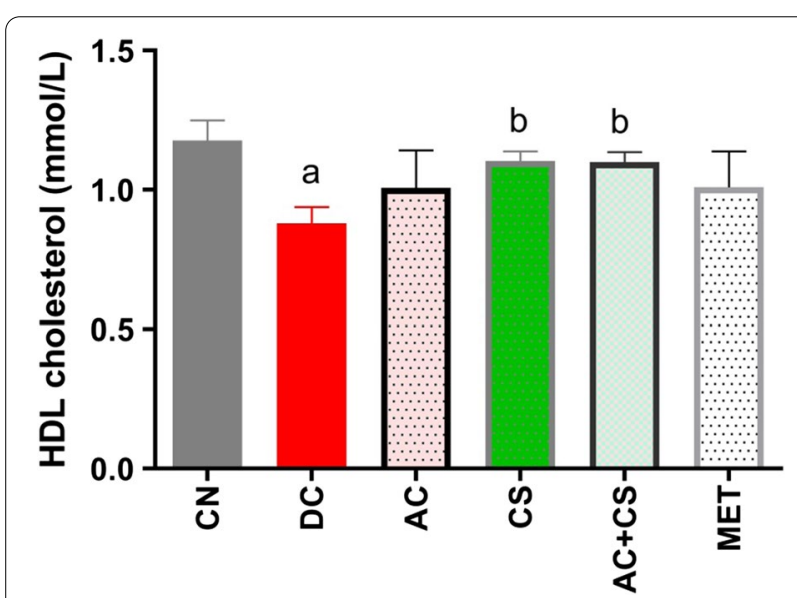

Fig. 4 Effect of Allium cepa and Cucumis sativa aqueous extracts on serum $\mathrm{HDL}$-cholesterol concentration in streptozotocin-induced diabetic rats. a significant when compared with control (CN), b significant when compared with diabetic control (DC)

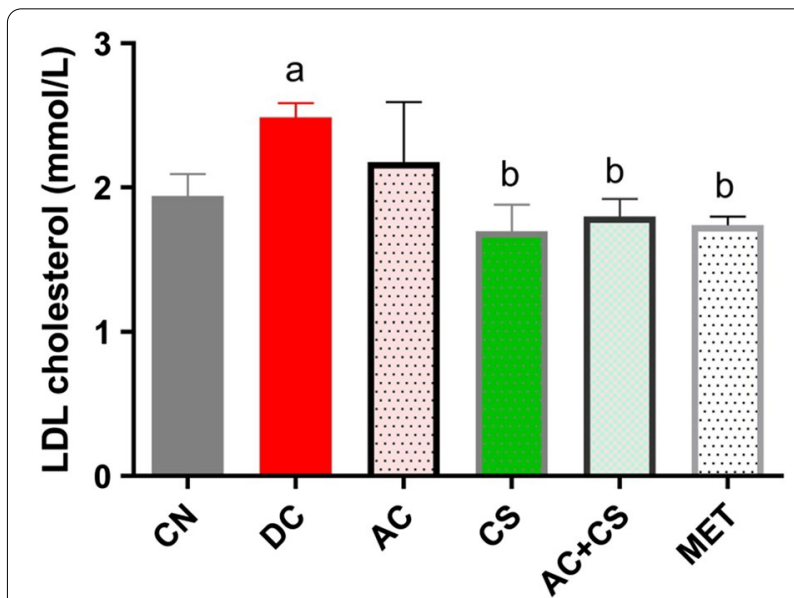

Fig. 6 Effect of Allium cepa and Cucumis sativa aqueous extracts on serum LDL-cholesterol concentration in streptozotocin-induced diabetic rats. a significant when compared with control (CN), b significant when compared with diabetic control (DC) 

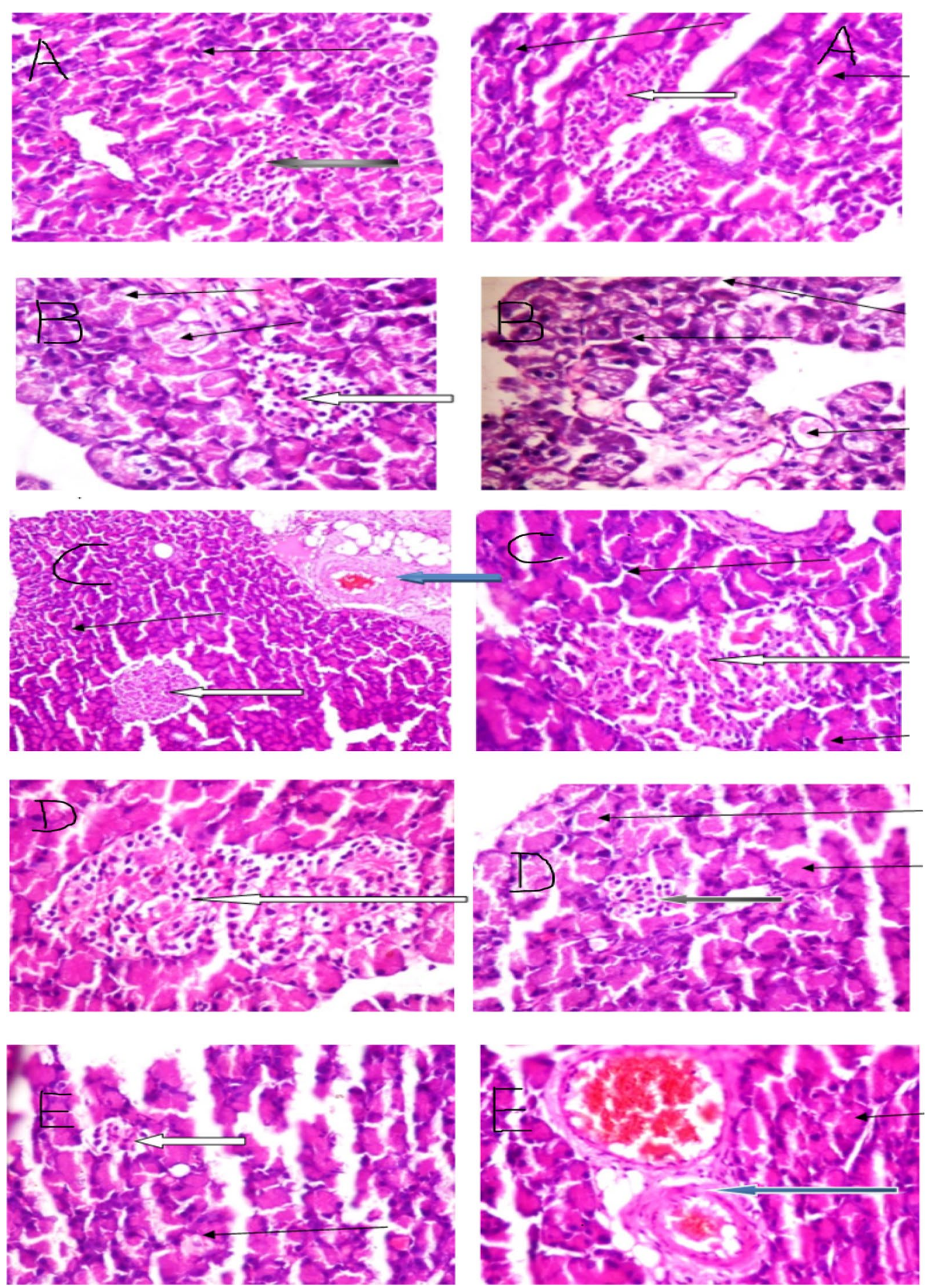

Fig. 7 A to $\mathbf{E}$ Photomicrographs of thin sections of representative pancreas of the different groups of animals

Group D animals (Diabetic animals treated with Allium cepa $(10 \mathrm{~mL} / \mathrm{kg} \mathrm{BW})$ showed degenerated and necrotized acinar cells (slender arrow). Normal interlobular connective tissues (green arrow) are seen. There are several normal compact islets of Langerhans and a few atrophic islets (white arrow).

Group E animals (Diabetic animals treated with Allium cepa and Cucumis sativa (1:1) formulation $(10 \mathrm{~mL} / \mathrm{kg}$ 
BW) showed normal serous acinar and zymogenic cells (slender arrow) containing abundant granular eosinophilic cytoplasm, mild vascular congestion seen (green arrow). Normal interlobular connective tissues (blue arrow) are seen. There are a few atrophic islets of Langerhans (white arrow).

\section{Discussion}

Diabetes mellitus remains a long-standing and global health challenge [1]. Although several therapeutic options are available for the management of the disease, unfortunately the disease is yet to have a cure [2]. This has necessitated the need to continuously search for a drug candidate with a curative potency. As a part of this pursuit, it is also important to take into cognizance common diets or foods that may play critical roles in the prevention or attenuation of the disease.

Vegetables like cucumber (Cucumis sativa) and onions (Allium cepa) are believed to be rich in natural compounds [5] which are capable of playing vital roles in glucose homeostasis or regulation [18]. It is on this basis, the present study was designed to evaluate the relative efficacy of Cucumis sativa and Allium cepa as well as their combined formulation in streptozotocin-induced diabetic rats.

The choice of streptozotocin as a diabetogenic agent in this study was informed by its ability to induce stable and insulin-dependent hyperglycemia in experimental animals. The results obtained indicate that the investigated botanicals could be vital in the fight against diabetes; particularly in terms of management, prevention and natural regression of the disease. Hence, regular consumption of onion (Allium cepa) and cucumber (cucumis sativa) may capacitate the body glucose regulatory machineries, consequently forestalling compromise in lipid homeostasis.

Compromised lipid metabolism is a metabolic disorder which is usually associated with uncontrolled diabetes mellitus and is undoubtedly key in the onset of diabetic complications $[19,20]$. The presence of rich amounts of dietary fiber, vitamins, minerals, and phytonutrients (flavonoids, ligands and triterpenes) in Allium cepa and Cucumis sativa may underscore their ability to protect against streptozotocin-induced alterations in the physiological levels of blood glucose and lipoprotein cholesterols (HDL- and LDL-cholesterols) in rats; as noted in this study. Antioxidants such as flavonoids, particularly quercetin, have been associated with blood sugar regulatory properties $[21,22]$. Similarly, soluble dietary fibers are well known for their binding roles in up-regulating and down-regulating the synthesis of HDL-cholesterol and LDL-cholesterol levels, respectively $[20,23]$

Consumption of vegetables and fruits has been known to contribute to human health and protect against disease
[7]. This is evidently due to the fact that they contain both nutrients and phyto-components with disease preventive properties. They are low in calories and capable of lowering the rates at which simple sugars are released from complex carbohydrates into the body system, consequently regulating the blood sugar level [24].

The hypoglycemic potential exhibited by Allium cepa and Cucumis sativa as well as their combined formulation in this study may be suggestive of the botanicals important roles in the improvement and/or regeneration of pancreatic beta cells as well as consequent stimulation of beta cells for insulin release.

There is also a possibility that hypoglycemic effects of Allium cepa and Cucumis sativa may have occurred through covalent modification of some glucose regulatory enzymes; and/or other pathways such as attenuation of endoplasmic reticulum (ER) stress; rather than increasing serum insulin level and creating extra-pancreatic effects. ER stress has been suggested to play a central role in the development of insulin resistance and diabetes by impairing insulin signaling [25].

Moreover, it is important to recall that the total triglycerides level in the serum was surprisingly decreased, howbeit not significantly in the diabetic control animals. This observation may be seen as the body's natural response to the unavailability of glucose for energy generation, hence the need for utilization of tissue triglycerides for energy purposes as an alternative source. Arguably, this 'biological flexibility' has the propensity to cause decline in serum total triglycerides as recorded in this study. Little wonder why treatments of the diabetic animals with Allium cepa, Cucumis sativa and their combined formulation which improved glucose assimilation into the body tissues, were noted to restore the serum triglycerides level.

In the same vein, the non-significant increase in serum total cholesterols noted in the diabetic control animals was unexpectedly exacerbated by treatments of the animals with Allium cepa, Cucumis sativa and their combined formulation. The reason for this is unclear. However, it is probably due to the ability of specific compounds in the botanicals to stimulate the synthesis of other high-density components of total cholesterols [5] (such as very high-density cholesterol (VHDL) as noted with HDL-cholesterol in this study.

\section{Conclusion}

The outcome of this study suggests that regular consumption of onions (allium cepa) and cucumber (cucumis sativa) may play vital roles in the combat against diabetes mellitus. We sincerely hope that findings from this study will be of benefit to diabetic patients and to the public at large. 


\section{Abbreviations}

HDL: High-density lipoprotein; LDL: Low-density lipoprotein.

\section{Acknowledgements}

We acknowledge the Laboratory technologists of the Department of Biochemistry, Lead City University, Ibadan, Nigeria.

\section{Authors' contributions}

All authors have read and approved the submission of this manuscript. $\mathrm{OMO}$ designed the project, AMA was involved in the laboratory works and internal review of the manuscript. OOD, TSU and OCC were involved in bench work and funding of the research. All authors read and approved the final manuscript.

\section{Funding}

Not applicable.

\section{Availability of data and materials}

All data are available upon request.

\section{Declarations}

\section{Ethics approval and consent to participate}

Ethical approval (Reference Number: LCUERB406) was obtained from Lead City University Ethical Review Board (LCU/ERB) to perform this animal research.

\section{Consent for publication}

Not applicable.

\section{Competing interest}

We have none to be declared.

\section{Author details}

${ }^{1}$ Department of Biochemistry, Lead City University, Ibadan, Nigeria. ${ }^{2}$ Department of Physiology and Pharmacology, Lead City University, Ibadan, Nigeria.

Received: 27 July 2021 Accepted: 19 October 2021

Published online: 08 November 2021

\section{References}

1. American Diabetes Association (2009) Diagnosis and classification of diabetes mellitus. Diabetes Care 32(Supplement 1):S62-S67

2. Jaacks LM, Siegel KR, Gujral UP, Narayan KV (2016) Type 2 diabetes: a 21st century epidemic. Best Pract Res Clin Endocrinol Metab 30(3):331-343

3. Dahiru T, Aliyu AA, Shehu A (2016) A review of population-based studies on diabetes mellitus in Nigeria. Sub-Saharan Afr J Med 3(2):59

4. Damas OM, Garces L, Abreu MT (2019) Diet as adjunctive treatment for inflammatory bowel disease: review and update of the latest literature. Curr Treat Options Gastroenterol 17(2):313-325

5. Barabási A-L, Menichetti G, Loscalzo J (2020) The unmapped chemical complexity of our diet. Nat Food 1(1):33-37

6. Udogadi NS, Onyenibe NS, Abdullahi MK (2019) Dietary management of diabetes mellitus with focus on Nigeria. Int J Diabetes Res 2(1):26-32
7. Yahia EM, García-Solís P, Celis MEM (2019) Contribution of fruits and vegetables to human nutrition and health. Postharvest physiology and biochemistry of fruits and vegetables. Elsevier, Amsterdam, pp 19-45

8. Akbar S (2020) Handbook of 200 medicinal plants: a comprehensive review of their traditional medical uses and scientific justifications. Springer, New York

9. Afolabi ET, Tame VT (2020) Effect of drying methods and packaging on the nutritional values of onions (Allium cepa L.) bulbs. Asian Plant Res J 47-55

10. Kim S-H, Jo S-H, Kwon Y-I, Hwang J-K (2011) Effects of onion (Allium cepa L.) extract administration on intestinal a-glucosidases activities and spikes in postprandial blood glucose levels in SD rats model. Int J Mol Sci 12(6):3757-3769

11. Mukherjee PK, Nema NK, Maity N, Sarkar BK (2013) Phytochemical and therapeutic potential of cucumber. Fitoterapia 84:227-236

12. Yoshinari O, Shiojima $Y$, Igarashi K (2012) Anti-obesity effects of onion extract in Zucker diabetic fatty rats. Nutrients 4(10):1518-1526

13. Allain CC, Poon LS, Chan CS, Richmond W, Fu PC (1974) Enzymatic determination of total serum cholesterol. Clin Chem 20(4):470-475

14. Fossati P, Principe $L$ (1982) Enzymatic colorimetric method to determination triglycerides. Clin Chem 28:2077

15. McNamara JR, Cole TG, Contois JH, Ferguson CA, Ordovas JM, Schaefer EJ (1995) Immunoseparation method for measuring low-density lipoprotein cholesterol directly from serum evaluated. Clin Chem 41(2):232-240

16. Lopes-Virella MF, Stone P, Ellis S, Colwell JA (1977) Cholesterol determination in high-density lipoproteins separated by three different methods. Clin Chem 23(5):882-884

17. Avwioro OG (2010) Histochemistry and tissue pathology, principle and technique. Claverianum Press, Nigeria

18. Karthiyayini T, Kumar R, Kumar KS, Sahu RK, Roy A (2015) Evaluation of antidiabetic and hypolipidemic effect of Cucumis sativus fruit in streptozotocin-induced-diabetic rats. Biomed Pharmacol J 2(2):351-355

19. Dunn FL (1992) Plasma lipid and lipoprotein disorders in IDDM. Diabetes 41(Supplement 2):102-106

20. Ighodaro OM, Akinloye OA, Ugbaja RN, Omotainse SO (2017) Sapium ellipticum (hochst.) pax ethanol leaf extract maintains lipid homeostasis in streptozotocin-induced diabetic rats. International Scholarly Research Notices

21. Jan AT, Kamli MR, Murtaza I, Singh JB, Ali A, Haq Q (2010) Dietary flavonoid quercetin and associated health benefits-an overview. Food Rev Int 26(3):302-317

22. Lakhanpal P, Rai DK (2007) Quercetin: a versatile flavonoid. Internet J Med Update 2(2):22-37

23. Omole J, Ighodaro O (2013) Comparative studies of the effects of egg yolk, oats, apple, and wheat bran on serum lipid profile of Wistar rats. International Scholarly Research Notices

24. Keller I, Tukuitonga C, The WHO/FAO Fruit and Vegetable Promotion Initiative (2005) In: I International symposium on human health effects of fruits and vegetables, vol 744, pp 27-37

25. Fonseca SG, Burcin M, Gromada J, Urano F (2009) Endoplasmic reticulum stress in $\beta$-cells and development of diabetes. Curr Opin Pharmacol $9(6): 763-770$

\section{Publisher's Note}

Springer Nature remains neutral with regard to jurisdictional claims in published maps and institutional affiliations. 